\title{
Colonization with selected antibiotic resistant bacteria among a cohort of Sri Lankan university students
}

Thilini Munasinghe1, Gihani Vidanapathirana², Shahlina Kuthubdeen', Asela Ekanayake³, Sacheera Angulmaduwa², Kunchana De Silva ${ }^{3}$, Susan Subhasinghe ${ }^{2}$, Ruwani Kalupahana ${ }^{4}$, Veranja Liyanapathirana ${ }^{3^{*}}$ (D) and Margaret $1 p^{5}$

\begin{abstract}
Background: Antibiotic Resistance is an imminent global public health threat. Antibiotic resistance emerged in healthcare settings and has now moved on to the community settings.

This study was conducted to identify the rates of asymptomatic colonization with selected antibiotic resistant organisms, (Methicillin Resistant Staphylococcus aureus (MRSA), Extended Spectrum Beta Lactamase (ESBL) producing Escherichia coli and Klebsiella spp and carbapenem resistant E.coli and Klebsiella spp) - among a group of university students in Sri Lanka. Identification of genetic determinants of MRSA and ESBL was an additional objective of the study.
\end{abstract}

Methods: A self - collected nasal swab and a peri-rectal swab collected after passing stools were obtained. Routine microbiological methods were used for the isolation S.aureus from the nasal swab and E.coli and Klebsiella species from the peri-rectal swab. Antibiotic sensitivity testing was performed as recommended by clinical and laboratory standard institute (CLSI).

Three (3) genes that are responsible for ESBL production; bla $a_{C T X-M}$, bla $a_{S H V}$, and blaTEM were tested using previously described primers and PCR procedures. Identification of MecA and PVL genes attributed to MRSA was also done with PCR.

Results: A total of 322 participants between 21 and 28 years were recruited representing 5 different faculties of study. Seventy one (22.0\%) were colonized with S.aureus and 14 among them with MRSA, making the MRSA colonization rate of $4.3 \%$. Forty five (15\%) of the participants were colonized with an ESBL producing E.coli or Klebsiella spp. No one was colonized with carbapenem resistant E.coli or Klebsiella species. Of the 45 ESBL producers the commonest genetic determinant identified was bla $a_{\mathrm{CTX}-\mathrm{M}}(n=36)$, while 16 isolates had bla $a_{\mathrm{TEM}}$ and 7 had bla $a_{\mathrm{SHV}}$. Similarly, of the 14 isolates identified as MRSA, 3 (21.4\%) were found to be PVL positive while 11 (78.6\%) were MecA positive.

Conclusions: A high rate of colonization with ESBL producing E.coli and Klebsiella species was noted in our study group.

Keywords: MRSA, ESBL, CRE, Colonization, University students

\footnotetext{
* Correspondence: veranjacl@yahoo.com; veranjacl@pdn.ac.lk

${ }^{3}$ Department of Microbiology, Faculty of Medicine, University of Peradeniya, Kandy, Sri Lanka

Full list of author information is available at the end of the article
}

C C The Author(s). 2021 Open Access This article is licensed under a Creative Commons Attribution 4.0 International License, which permits use, sharing, adaptation, distribution and reproduction in any medium or format, as long as you give appropriate credit to the original author(s) and the source, provide a link to the Creative Commons licence, and indicate if changes were made. The images or other third party material in this article are included in the article's Creative Commons licence, unless indicated otherwise in a credit line to the material. If material is not included in the article's Creative Commons licence and your intended use is not permitted by statutory regulation or exceeds the permitted use, you will need to obtain permission directly from the copyright holder. To view a copy of this licence, visit http://creativecommons.org/licenses/by/4.0/ The Creative Commons Public Domain Dedication waiver (http://creativecommons.org/publicdomain/zero/1.0/) applies to the data made available in this article, unless otherwise stated in a credit line to the data. 


\section{Introduction}

Antimicrobial resistance (AMR) has emerged as one of the principle public health concerns of this era. AMR has spread globally, compromising the ability to use antibiotics to treat infectious diseases. Resistant organisms, initially found in health care environments are now being increasingly found in community setting. Asymptomatic colonization with resistant organisms may subsequently cause serious infections in other sites of the given individual or in susceptible individuals [1].

AMR is a key challenge faced by the health care sector in Sri Lanka [2]. Along with the emergence of Gram negative resistance, resistance in Gram positive bacteria continue to pose a challenge. Infections caused by Methicillin Resistant Staphylococcus aureus (MRSA), ESBL producing enterobacteriaceae (ESBLE) and carbapenem resistant enterobacteriaceae (CRE) in hospital settings has been well studied in Sri Lanka [3]. ESBLE are emerging as causative agents in community onset infections [4]. However, data on colonization with these resistant bacteria among healthy young adults is limited. Colonized individuals may act as a reservoir for the spread of these bacteria in the community and studies have shown that people colonized with ESBLE are likely to contribute to others getting colonized with similar bacteria than non-human factors [5].

This study was conducted to identify the rates of colonization with selected antibiotic resistant organisms among a group of university students in Sri Lanka and to identify factors associated with such colonization.

\section{Materials and methods}

This was a descriptive cross-sectional study which included undergraduate students of University of Peradeniya between 18 to 28 years of age. Nasal swabs and peri-anal swabs were collected from the participants from December, 2017 to October 2018. Ethical approval for the study was obtained from the Ethics Review Committee, Faculty of Medicine, University of Peradeniya (2017/EC/29).

\section{Subject enrolment and sample collection process}

Three hundred twenty-two participants were recruited using convenience sampling method. Samples were selfcollected by the participants. They were provided with two swabs. Participants were advised to insert one swab in to both nostrils, rotate to touch all sides of the nasal wall and insert back to the sheath. For collecting the peri-anal swab, participants were advised to insert the swab up to $1 \mathrm{~cm}$ through the anal orifice and touch the anal wall, followed by touching the peri-rectal area, after passing stool, before cleaning. The collected specimens were transported to the laboratory within 2 hours after collection.

\section{Laboratory procedure}

Collected nasal swabs were processed to isolate Staphylococcus aureus using conventional laboratory techniques including $6.5 \% \mathrm{NaCl}$ tolerance, growth on Manitol Salt Agar plates, Gram staining, catalase test, slide and tube coagulase tests and DNase test.

Peri-anal swabs were processed to isolate ESBL producing Enterobacteriaceae species. The identification of the Escherichia coli, Klebsiella pneumoniae or Klebsiella oxytoca species were based on the Cowan and Steel's manual [6]. Quality-controlled MacConkey agar plates supplemented with ceftazidime $(1 \mathrm{mg} / \mathrm{L})$ were used for the tentative identification of ESBL producers.

Organisms thus identified were inoculated on 15-20\% glycerol broth and stored in $-80{ }^{\circ} \mathrm{C}$ till further testing.

\section{Antibiotic sensitivity testing (ABST)}

ABSTs were done using disc diffusion method following the Clinical and Laboratory Standard Institute (CLSI) guide [7]. For Staphylococcus aureus, the antibiotics used were cefoxitin $(30 \mu \mathrm{g})$, gentamicin $(10 \mu \mathrm{g})$, ciprofloxacin $(5 \mu \mathrm{g})$, clindamycin $(2 \mu \mathrm{g})$, fusidic acid $(5 \mu \mathrm{g})$ and erythromycin $(15 \mu \mathrm{g})$. For E.coli and Klebsiella species, the antibiotics used for the study were cefotaxime $(30 \mu \mathrm{g})$, ceftazidime $(30 \mu \mathrm{g})$, imipenem $(10 \mu \mathrm{g})$, meropenem $(10 \mu \mathrm{g})$, aztreonam $(30 \mu \mathrm{g})$, gentamicin $(10 \mu \mathrm{g})$, ciprofloxacin $(5 \mu \mathrm{g})$ and levofloxacin $(5 \mu \mathrm{g})$.

Isolates which were with zone diameters $\leq 21 \mathrm{~mm}$ for cefoxitin $(30 \mu \mathrm{g})$ for Staphylococcus aureus were considered as MRSA isolates [7].

Isolates with zone diameters $\leq 22 \mathrm{~mm}$ and $\leq 27 \mathrm{~mm}$ for antibiotics ceftazidime $(30 \mu \mathrm{g})$ and/or cefotaxime $(30 \mu \mathrm{g})$ respectively for both Escherichia coli. and Klebsiella spp. were considered as fulfilling ESBL screening criteria for ESBL production. ESBL confirmatory testing was performed on these isolates. Ceftazidime $(30 \mu \mathrm{g})$ and cefotaxime $(30 \mu \mathrm{g})$ were used alone and in combination with clavulanic acid [ceftazidime $(30 \mu \mathrm{g}) /$ ceftazidime-clavulanate $(30 / 10 \mu \mathrm{g})$ and cefotaxime $(30 \mu \mathrm{g} /$ cefotaxime-clavulanate $(30 /$ $10 \mu \mathrm{g})]$ were used for the confimatory testing. The results were interpreted according to CLSI guidelines [7].

\section{DNA extraction}

Simple boil lysis method was used to extract the DNA from the identified MRSA and ESBL species.

Identification of genetic determinants of ESBL production Three (3) genes that are responsible for ESBL production; bla $a_{\mathrm{CTX}-\mathrm{M}}, b l a_{\mathrm{SHV}}$, and $b l a_{\mathrm{TEM}}$ were tested using previously described primers and PCR procedures [8].

\section{Identification of PVL and mecA genes}

Previously described primers were used for identification of $\mathrm{MecA}$ (162 bp) and PVL (85 bp) genes respectively [9]. 


\section{Data analysis}

SPSS software version 22 was used for data analysis (IBM statistics). A $p$ value of $<0.05$ was taken as being statistically significant. Percentage of MRSA and ESBL colonization among the study population was calculated. Factors associated with antibiotic resistant bacteria were identified using Chi square test or the Fisher's Exact test. Of the ESBL producers, proportions of isolates carrying each genetic determinant, and proportion of MRSA isolates with $P V L$ gene and $M e c A$ genes were calculated.

\section{Results}

\section{Demographic details}

During the study period, a total of 322 samples were collected. The participants' ages ranged from 20 to 28 years (Mean: 23.7 years, SD 1.4). The numbers of female and male students were 166 (51.6\%) and 156 (48.4\%) respectively. Of the 322 participants, 210 (65.2\%) were from health science related faculties and 112 (34.8\%) were from non-health related faculties. The number of participants residing at university residential facilities were 225 $(69.9 \%)$ and 97 were $(30.1 \%)$ day scholars. There were 136 (42.2\%) participants who used antibiotics during the 3 months preceding sample collection and 15 (4.7\%) participants were having chronic diseases.

\section{Colonization with Staphylococcus aureus and MRSA}

Among the 322 participants, Staphylococcus aureus was isolated from $71(22 \%)$ participants. This included 14 (4.3\%) participants who were colonized with Methicillin Resistant Staphylococcus aureus (MRSA) isolates.

Nine of the 156 males (5.8\%) and 5 of the 166 females (3\%) were colonized with MRSA. None of the factors studied were significantly associated with colonization with MRSA (Table 1).
Antibiotic sensitivity testing of Staphylococcus aureus and MRSA isolates

Of the 71 participants colonized with Staphylococcus aureus, 57 were colonized with Methicillin Sensitive Staphylococcus aureus (MSSA), while 14 were colonized with MRSA. Their sensitivities are given in Table 2.

\section{Identification of PVL and MecA genes}

Of the 14 isolates identified as MRSA, 3 isolates were found to be $P V L$ positive while 11 were $M e c A$ positive.

\section{Isolation of Escherichia coli and Klebsiella species from ESBL screening plates}

Number of samples which yielded Gram negative bacilli was 108 (33.5\%). Of these 108 cultures 134 Gram negative bacterial isolates were obtained. There were 65 (48.5\%) E. coli isolates and 3 (2.2\%) Klebsiella pneumoniae isolates while others were Gram negative cocci and were not included in further analysis.

\section{Colonization rates for ESBL producers}

Forty five of the 322 (14.0\%) participants were colonized with ESBL producing E. coli $(44,13.7 \%)$ or K. pneumoniae $(1,0.3 \%)$ isolates.

Factors associated with colonization with ESBL producers Twenty four of the 156 males (15.4\%) and 21 of the 166 females (12.7\%) were colonized with ESBL producers. This difference was not statistically significant $(p=0.52$, Chi square test). Having a chronic disease was significantly associated with colonizing with ESBL producers (33.3\% colonization among those with chronic diseases vs $13.0 \%$ among those without chronic diseases) (Table 3).

Table 1 Association of variables with MRSA

\begin{tabular}{|c|c|c|c|c|}
\hline \multirow[t]{2}{*}{ Variables } & & \multicolumn{2}{|l|}{ Number of participants $(n=322)$} & \multirow[t]{2}{*}{ Significance $^{*}$} \\
\hline & & Participants colonized with MRSA & Participants not colonized MRSA & \\
\hline \multirow[t]{2}{*}{ Sex } & Male $(n=156)$ & $9(5.8 \%)$ & 147 (94.2\%) & $0.28^{*}$ \\
\hline & Female $(n=166)$ & $5(3.0 \%)$ & $161(97.0 \%)$ & \\
\hline \multirow[t]{2}{*}{ Faculty } & Health Science related $(n=210)$ & $10(4.8 \%)$ & $200(95.2 \%)$ & $0.78 \wedge$ \\
\hline & None Health related $(n=112)$ & $4(3.6 \%)$ & $108(96.4 \%)$ & \\
\hline \multirow[t]{2}{*}{ Antibiotic intake } & Yes $(n=133)$ & $8(6.0 \%)$ & $125(94.0 \%)$ & $0.27^{*}$ \\
\hline & No $(n=189)$ & $6(3.2 \%)$ & $183(96.8 \%)$ & \\
\hline \multirow[t]{2}{*}{ Chronic diseases } & Yes $(n=15)$ & $1(6.7 \%)$ & $14(93.3 \%)$ & $0.49 \wedge$ \\
\hline & No $(n=307)$ & $13(4.2 \%)$ & $294(95.8 \%)$ & \\
\hline \multirow[t]{2}{*}{ Residence } & Residents $(n=225)$ & $7(3.1 \%)$ & $218(96.9 \%)$ & $0.09 \wedge$ \\
\hline & Day scholars $(n=97)$ & $7(7.2 \%)$ & $90(92.8 \%)$ & \\
\hline
\end{tabular}

${ }^{*} p$ value calculated using the Chi-square test

$\wedge p$ value calculated using Fisher's Exact test 
Table 2 Susceptibility rates for MRSA and MSSA strains

\begin{tabular}{lll}
\hline & MSSA strains $(\boldsymbol{n}=\mathbf{5 7})$ & MRSA strains $(\boldsymbol{n}=\mathbf{1 4})$ \\
\hline Gentamicin $(10 \mu \mathrm{g})$ & $54(94.7 \%)$ & $13(92.9 \%)$ \\
Ciprofloxacin $(5 \mu \mathrm{g})$ & $42(73.7 \%)$ & $10(71.4 \%)$ \\
Clindamycin $(2 \mu \mathrm{g})$ & $50(87.7 \%)$ & $11(78.6 \%)$ \\
Including inducible resistant isolates & & $14(100.0 \%)$ \\
Clindamycin $(2 \mu \mathrm{g})$ & $50(87.7 \%)$ & $12(85.7 \%)$ \\
Excluding inducible resistant isolates & & $4(28.6 \%)$ \\
Fusidic acid $(5 \mu \mathrm{g})$ & $49(86.0 \%)$ & $24(42.1 \%)$ \\
Erythromycin $(15 \mu \mathrm{g})$ & &
\end{tabular}

\section{Antibiotic sensitivity testing}

All ESBL producing isolates were susceptible for carbapenems. Antibiotic sensitivity rates for ESBL producers are given in Table 4 .

\section{Genetic determinants of ESBL producers}

Of the 45 ESBL producers the commonest genetic determinant identified was bla СТХ-М $(n=36)$, while 16 isolates had $b l a_{\mathrm{TEM}}$ and 7 had $b l a_{\mathrm{SHV}}$. (Table 5).

\section{Colonization rates for $\mathrm{CRE}$}

All isolates were sensitive to imipenem and meropenem. None of the $322(0.0 \%)$ participants were colonized with CRE.

\section{Co-colonization with MRSA and ESBLE}

Only one $(0.31 \%)$ participant was co-colonized with both MRSA in nasal region and ESBLE in the peri anal region.

\section{Discussion}

In the current study, we have assessed colonization of Methicillin Resistant Staphylococcus aureus (MRSA), extended spectrum beta lactamase producing enterobacteriaceae (ESBL) and carpabenem resistant enterobacteriaceae (CRE) among a selected group of university students in Sri Lanka.

According to the present study, rate of colonization of MRSA was $4.3 \%$. Of the 14 isolates identified as MRSA, 3 (21.4\%) were found to be $P V L$ positive while 11 (78.6\%) were $M e c A$ positive.

In this study MRSA colonization was higher in health science related students $(4.8 \%)$ than in non-health science related students (3.6\%). However, this difference was not statistically significant.

A similar study has been carried out in Rajarata University of Sri Lanka, located in another province of Sri Lanka, in order to evaluate the relationship between the exposure to healthcare settings and colonization with methicillin-resistant Staphylococcus aureus among medical students. The percentage of MRSA colonization found before clinical exposure and after 2.5 years of exposure was 6.36 and $49.57 \%$, respectively [10]. However, the MRSA colonization rate after the clinical exposure was relatively higher than to the present study. Our study sample consisted of students from both health and non-health related faculties, and we did no check the exposure to

Table 3 Association of variables with colonization by ESBL producers

\begin{tabular}{|c|c|c|c|c|}
\hline \multirow[t]{2}{*}{ Variables } & & \multicolumn{2}{|l|}{ Number of participants $(n=322)$} & \multirow[t]{2}{*}{ Significance ${ }^{*}$} \\
\hline & & Participants colonized with ESBL & Participants not colonized ESBL & \\
\hline \multirow[t]{2}{*}{ Sex } & Male $(n=156)$ & $24(15.4 \%)$ & $132(84.6 \%)$ & $0.52^{*}$ \\
\hline & Female $(n=166)$ & $21(12.7 \%)$ & $145(87.3 \%)$ & \\
\hline \multirow[t]{2}{*}{ Faculty } & Health Science related $(n=210)$ & $31(14.8 \%)$ & $179(85.2 \%)$ & $0.35^{*}$ \\
\hline & None Health related $(n=112)$ & $14(12.5 \%)$ & $98(87.5 \%)$ & \\
\hline \multirow[t]{2}{*}{ Antibiotic intake } & Yes $(n=136)$ & $23(17.3 \%)$ & $110(82.7 \%)$ & $0.19^{*}$ \\
\hline & No $(n=186)$ & $22(11.6 \%)$ & $167(88.4 \%)$ & \\
\hline \multirow[t]{2}{*}{ Chronic diseases } & Yes $(n=15)$ & $5(33.3 \%)$ & $10(66.7 \%)$ & $0.04 \wedge$ \\
\hline & No $(n=307)$ & $40(13.0 \%)$ & $267(87.0 \%)$ & \\
\hline \multirow[t]{2}{*}{ Residence } & Residents $(n=225)$ & $30(13.3 \%)$ & $195(86.7 \%)$ & $0.72^{*}$ \\
\hline & Non-residents $(n=97)$ & $15(15.5 \%)$ & $82(84.5 \%)$ & \\
\hline
\end{tabular}

${ }^{*} p$ value calculated using the Chi-square test

$\wedge p$ value calculated using Fisher's Exact test 
Table 4 Antibiotic susceptibility rates of ESBL producers

\begin{tabular}{ll}
\hline & ESBL producers N (\%) \\
\hline Cefotaxime $(30 \mu \mathrm{g})$ & $0(0.0 \%)$ \\
Ceftazidime $(30 \mu \mathrm{g})$ & $1(2.2 \%)$ \\
Aztreonam $(30 \mu \mathrm{g})$ & $1(2.2 \%)$ \\
Meropenem $(10 \mu \mathrm{g})$ & $45(100 \%)$ \\
Imipenem $(10 \mu \mathrm{g})$ & $45(100 \%)$ \\
Ciprofloxacin $(5 \mu \mathrm{g})$ & $18(40.0 \%)$ \\
Levofloxacin $(5 \mu \mathrm{g})$ & $22(48.8 \%)$ \\
Gentamicin $(10 \mu \mathrm{g})$ & $43(95.5 \%)$ \\
\hline
\end{tabular}

clinical settings in health-related students. Therefore, we cannot compare the effect of health care facility exposure. However, the overall colonization rate in our study, and the colonization rate among nonclinical students in the cited study are similar.

There are a number of similar studies conducted in other countries with regards to the MRSA colonization among university students. A study detected the prevalence of MSSA and MRSA among medical students in Saudi Arabia, using molecular approaches revealed a colonization rate of $18.7 \%$ for Staphylococcus aureus and 6.7\% for MRSA [11]. These rates are similar to what we found through conventional culture. Prevalence of nasal carriers of MRSA has been evaluated in a group of medical students in Jordan and 2.4\% MRSA colonization was found [12]. According to the findings of the study, $S$. aureus nasal colonization was significantly associated with male gender and chronic illnesses. All the MRSA isolates were positive for $m e c A$ gene. Higher rates of $m e c A$ positive MRSA was observed in our study as well. Nevertheless, there were no significant factors associated with MRSA colonization in our study. Another study done in Taiwan on prevalence and the risk factors for MRSA colonization among adults in community settings has given a colonization rate of $3.8 \%$ [13]. It is stated that $S$. aureus has a specific niche preference for the anterior nostrils in adults [14]. This nasal carriage rate was also reported approximately $10 \%$ in the community [15].

Table 5 Genetic determinants found on ESBL producers

\begin{tabular}{ll}
\hline Gene & No of isolates \\
\hline bla $_{S H V}$ only & 0 \\
bla $_{T E M}$ only & 3 \\
bla $a_{C T X M}$ only & 29 \\
bla $a_{S H V+} b l a_{T E M}$ & 6 \\
bla $a_{C T X-M+} b l a_{S H V}$ & 0 \\
bla $a_{C T X-M+} b l a_{T E M}$ & 6 \\
bla $a_{C T X-M+} b l a_{T E M+} b l a_{S H V}$ & 1 \\
Total & 45 \\
\hline
\end{tabular}

Present study also supported the fact that nasal carriage has become a mode of persistence and may contribute to the spread of MRSA.

The reported prevalence of colonization with MRSA differs between institutions and geographic regions which might be due to differences in terms of study design, sample size and methods, samples used for MRSA detection. In addition to that, differences in actual colonization or changes in detection due to sample collection (nasal vs nasal, axillary, throat and groin) and processing methods might have affected the deviation in the colonizing rates.

When considering the antibiotic susceptibility rates of the isolated Staphylococcus aureus, the highest resistance was observed for erythromycin in both MSSA and MRSA. This was observed in another study where all the MRSA isolates were resistant to penicillin and erythromycin [16]. In another study done among school children in Ethiopia, susceptibility rates of gentamicin and erythromycin were 84.6 and $38.5 \%$ for MRSA and 98.5 and $82.3 \%$ for MSSA respectively [17]. These correlate with our study findings. MRSA globally has become multi-drug resistant due to acquisition of other genetic determinants of resistance [18].

The sensitivity of CA-MRSA related to infections was also found to be quite similar to findings of the current study. According to a study done relate to skin and soft tissue infections, MRSA susceptibility to erythromycin and clindamycin were 23.1 and $80.7 \%$ respectively [19]. Susceptibility rates in the study done in tertiary care hospital for erythromycin, clindamycin, ciprofloxacin, gentamicin was $35,48.8,28$ and $32 \%$ [20].

Unlike community acquired MRSA (CA-MRSA), healthcare associated MRSA (HA-MRSA) has been studied extensively in Sri Lanka. Analysis of Staphylococcus aureus isolates obtained from a private hospital has identified an MRSA proportion of $42 \%$ [21]. Majority of the isolated MRSA had antibiograms compatible with community acquired MRSA which indicates the possibility of crossing over of antimicrobial resistance from health care settings into the community in Sri Lanka. In another study conducted to compare molecular characteristics of CAMRSA and HAMRSA strains isolated at the National Hospital of Sri Lanka, the proportion of HA-MRSA was $79 \%$ while CA-MRSA was $21 \%$. The proportion of PVL gene among HA-MRSA isolates was $3.8 \%$ whereas proportion of $P V L$ among CA-MRSA isolates was $95.2 \%$ [22]. In our study, the proportion of PVL positive isolates was more similar to the proportion reported from HA-MRSA isolates in this study.

However, it is now evident that there are lineages of CA-MRSA that are $P V L$ negative. These clones have also shown a global distribution [23]. As we did not do indept molecular analysis on our isolates, we are unable to 
comment on this. However, the low rate of PVL prevalence does not exclude the isolates from being community origin.

In this study, the rate of colonization of ESBL producers was $(n=45) 14.0 \%$ and all except one isolate were E. coli. Of the 45 ESBL producers the commonest genetic determinant identified was bla $a_{\mathrm{CTX}-\mathrm{M}}(n=36)$, while 16 isolates had $b l a_{\mathrm{TEM}}$ and 7 had $b l a_{\mathrm{SHV}}$.

Our ESBL colonizing rates were parallel to several other studies found in literature. In a study done among Mozambican university students, the proportion of students colonized with community acquired ESBL producers was found to be $20 \%$ [24]. Another study done among children attending pre-school childcare facilities in Laos has identified $23.2 \%$ of the study population to be colonised with ESBL producers [25]. The rate of colonization we found in the current study is much higher than the rate of vaginal colonization found among pregnant females presenting for delivery at Teaching Hospital Peradeniya [26]. The differences in sampling sites and study cohorts may be possible reasons for this difference. Further, a preliminary study in Switzerland has shown that vagina-perineal swab has a lower sensitivity of detecting ESBL carriage in pregnant women. Further, the ESBL carriage among pregnant women has found to be lower than the general population. Both these also could explain the lower rates of the study by Nanayakkara et al. compared to the current study [27].

In the present study, none of factors studied were significantly associated with colonization with ESBL producers other than presence of chronic disorders. Prevalence of ESBL producers was significantly high (33.3\%) in students who suffer from chronic diseases than in students who did not (13\%). Co-morbid conditions are a recognized risk factor for colonization with ESBL producers [28]. Frequent exposure of individuals with chronic diseases to health care settings might be the reason behind this. Previous exposure to antibiotics increases the chance of getting colonized with resistant bacteria. While the difference between those who recalled having used antibiotics in the 3 months before the study and those who did not, was not statistically significant, the former group had a higher colonization rate in the current study.

The susceptibility rates of ESBL producers for cefotaxime, ceftazidime, aztreonam, meropenem, imipenem, ciprofloxacin, levofloxacin and gentamicin were 0.0, 2.2, $2.2,100,100,40,48.8$, and $95.5 \%$. The study done among Mozambican university students, E. coli and Klebsiella spp. combined demonstrated 63 and 34\% resistance rates of ceftazidime and ciprofloxacin respectively [24].
All ESBL producers were not resistant to both cefotaxime and ceftazidime which emphasizes the need to use both drugs in screening for ESBL production. The lower rate of susceptibility to levofloxacin is a reason to be concerned.

Among the ESBL producing enterobacteriaceae, the commonest genetic determinant of resistance currently is $b l a_{\text {СтХ-M }}$ which is in agreement with our findings.

According to the current study there was no colonization of CRE among the study population. This is supported by several studies done on community acquired CRE. Study on colonization with ESBLE and CRE in international travellers returning to Germany has detected no CRE [29]. Another study done in children attending pre-school child care facilities in Laos also observed no CRE [25]. Kumudunie et al. has reported an alarming rate of CRE and the emergence of $b l a_{\mathrm{KPC}}$ harboring $K$. pneumoniae in Sri Lanka among clinical isolates [30]. Other clinical studies have also demonstrated higher number of CRE [31]. This emphasizes the need of a further studies and continuous monitoring of CRE in the community.

We did not sequence the potential genetic determinants of ESBL production. This maybe a limitation as some narrow spectrum beta lactamases may also be identified through these primers. Further our samples were self-collected. Then though this may introduce a heterogeneity, self-collected nasal swabs and peri-rectal swabs have been shown to be effective methods in community surveillance [32-34]((Gambin 2012, Hogan 2016, Sun 2017). Further, peri-rectal swabs have also been shown as an effective alternative to collecting stool samples and used in multiple studies previously [35, 36] (Lautenback 2005, Blythe 2016).

\section{Conclusion}

The asymptomatic colonization rate of CA-MRSA was $4.3 \%$ in the studied group of university undergraduates while the asymptomatic colonization rate of ESBL producers was $14 \%$ including 13.7 and $0.3 \%$ of $E$. coli and $K$. pneumoniae respectively. CRE was not found as a colonizer among the study group.

\footnotetext{
Abbreviations

MRSA: Methicillin resistant Staphylococcus aureus; MSSA: Methicillin Sensitive Staphylococcus aureus; CA-MRSA: Community Acquired Methicillin resistant Staphylococcus aureus; HA-MRSA: Healthcare Associated Methicillin resistant Staphylococcus aureus; ESBL: Extended Spectrum Beta Lactamase; ESBLE: ESBL producing enterobacteriaceae; CRE: Carbapenem Resistant

Enterobacteriaceae; CLSI: Clinical and Laboratory Standard Institute; PCR: Polymerase Chain Reaction; AMR: Antimicrobial resistance;

DNA: Deoxyribonucleic acid
}

Acknowledgements 


\section{Authors' contributions}

TM - Bulk of sample collection and wet laboratory work, along with primary analysis. GV - Sample collection, wet lab work, molecular work and writing up of the manuscript. SK - Molecular laboratory work. AE - Technical support for the study. SA - Sample collection and laboratory work. KDS - Project coordination. SS - Project coordination. RK - Study design, project coordination. VL - Conceptualization, study design, supervision of the laboratory work, data analysis and interpretation, manuscript writing, editing and finalizing. MIP- Conceptualization and study design. The author(s) read and approved the final manuscript.

\section{Funding}

This study was funded by the University of Peradeniya Research Grant (URG/ 2016/96/M). Funding body approved the study design in the approval of the grant for the study but has no role in the collection, analysis, and interpretation of data and in writing the manuscript.

\section{Availability of data and materials}

The datasets used and analysed during the present study are available on the corresponding author on reasonable request.

\section{Declarations}

\section{Ethics approval and consent to participate}

Ethical approval for the study was obtained from the Ethics Review Committee, Faculty of Medicine, University of Peradeniya (2017/EC/29). Informed written consent was taken by study participants.

\section{Consent for publication}

Not applicable.

\section{Competing interests}

Authors have declared no competing interest.

\section{Author details}

${ }^{1}$ Postgraduate Institute of Science, University of Peradeniya, Kandy, Sri Lanka. ${ }^{2}$ Faculty of Medicine, University of Peradeniya, Kandy, Sri Lanka. ${ }^{3}$ Department of Microbiology, Faculty of Medicine, University of Peradeniya, Kandy, Sri Lanka. ${ }^{4}$ Department of Veterinary Public Health and Pharmacology, Faculty of Veterinary Medicine and Animal Science, University of Peradeniya, Kandy, Sri Lanka. ${ }^{5}$ Department of Microbiology, Faculty of Medicine, The Chinese University of Hong Kong, Hong Kong, Hong Kong SAR.

Received: 27 August 2020 Accepted: 4 June 2021 Published online: 15 June 2021

\section{References}

1. Woerther PL, Andremont A, Kantele A. Travel-acquired ESBL-producing Enterobacteriaceae: impact of colonization at individual and community level. J Travel Med. 2017;24(suppl1):29-34.

2. Liyanapathirana VC, Thevanesam V. Combating antimicrobial resistance. Sri Lankan J Infect Dis. 2016;6(2):72-88. https://doi.org/10.4038/sljid.v6i2.8119.

3. Fernando MM, Luke WA, Miththinda JK, Wickramasinghe RD, Sebastiampillai BS, Gunathilake MP, et al. Extended spectrum beta lactamase producing organisms causing urinary tract infections in Sri Lanka and their antibiotic susceptibility pattern-a hospital based cross sectional study. BMC Infect Dis. 2017;17(1):138. https://doi.org/10.1186/s12879-017-2250-y.

4. Devi LS, Broor S, Rautela RS, Grover SS, Chakravarti A, Chattopadhya D. Increasing Prevalence of Escherichia coli and Klebsiella pneumoniae Producing CTX-M-Type Extended-Spectrum Beta-Lactamase, Carbapenemase, and NDM-1 in Patients from a Rural Community with Community Acquired Infections: A 3-Year Study. Int J Appl Basic Med Res. 2020;10(3):156-63. https://doi.org/10.4103/ijabmr.IJABMR_360_19 Epub 2020 Jul 11. PMID: 33088736; PMCID: PMC7534723.

5. Mughini-Gras L, Dorado-García A, van Duijkeren E, van den Bunt G, Dierikx CM, Bonten MJM, et al. Attributable sources of community-acquired carriage of Escherichia coli containing $\beta$-lactam antibiotic resistance genes: a population-based modelling study. Lancet Planet Health. 2019;3(8):e357-69. https://doi.org/10.1016/S2542-5196(19)30130-5 Erratum in: lancet planet health. 2019 Oct;3(10):e408. PMID: 31439317.
6. Cowan ST. Cowan and Steel's manual for the identification of medical bacteria. Cambridge: Cambridge University Press; 2004.

7. CLSI Performance Standards for Antimicrobial Disk Susceptibility Tests; Approved Standard. CLSI document MT-100. 28th ed. Wayne: Clinical and Laboratory Standards Institute; 2018.

8. Monstein HJ, Ostholm-Balkhed A, Nilsson MV, Nilsson M, Dornbusch K, Nilsson LE. Multiplex PCR amplification assay for the detection of blaSHV, blaTEM and blaCTX-M genes in Enterobacteriaceae. APMIS. 2007;115(12): 1400-8. https://doi.org/10.1111/j.1600-0463.2007.00722.x.

9. EURL-AR (2012). Protocol For Pcr Amplification Of Meca, Mecc (Mecalga251), Spa And Pvl Recommended By The Eurl-Ar. Available from https://www. eurl-ar.eu/CustomerData/Files/Folders/21-protocols/279_pcr-spa-pvl-mecamecc-sept12.pdf. Last accessed on 29 July 2020

10. Jayaweera JAAS, Pilapitiya S, Kumbukgolla W. The relationship between the exposure to healthcare settings and colonization with methicillin-resistant Staphylococcus aureus among medical students. Germs. 2020;10(1):34-43. https://doi.org/10.18683/germs.2020.1183 Erratum in: Germs. 2020 Sep 1; 10(3):279. PMID: 32274358; PMCID: PMC7117885.

11. Zakai SA. Prevalence of methicillin-resistant Staphylococcus aureus nasal colonization among medical students in Jeddah, Saudi Arabia. Saudi Med J. 2015;36(7):807-12. https://doi.org/10.15537/smj.2015.7.11609.

12. Al-Tamimi M, Himsawi N, Abu-Raideh J, Al-jawaldeh H, Mahmoud SA, Hijjawi $\mathrm{N}$, et al. Nasal colonization by methicillin-sensitive and methicillinresistant Staphylococcus aureus among medical students. J Infect Dev Countries. 2018;12(05):326-35. https://doi.org/10.3855/jidc.9908.

13. Wang J, et al. Prevalence of and risk factors for colonization by methicillinresistant Staphylococcus aureus among adults in community settings in Taiwan. J Clin Microbiol. 2009;47(9):2957-63. https://doi.org/10.1128/JCM. 00853-09.

14. Kluytmans JAN, Verbrugh $\mathrm{H}$. Nasal Carriage of Staphylococcus aureus: Epidemiology, Underlying Mechanisms, and Associated Risks. Clin Microbiol Rev. 1997;10(3):505-20. https://doi.org/10.1128/CMR.10.3.505.

15. Que YA, Moreillon P. Staphylococcus aureus (Including Staphylococcal Toxic Shock). In: Mandell GL, Bennett JE, Dolin R, editors. Mandell, Douglas and Bennett's Principle and practice of Infectious Diseases. Philadelphia: Elsivier Saunders; 2010. p. 2543-78.

16. Demirel G, Findik D, Dagi HT, Arslan U. Community-acquired methicillinresistant Staphylococcus aureus and genotypes. Southeast Asian J Trop Med Public Health. 2008;45(6):1401-9.

17. Kejela T, Bacha K. Prevalence and antibiotic susceptibility pattern of methicillin-resistant Staphylococcus aureus (MRSA) among primary school children and prisoners in Jimma town, Southwest Ethiopia. Ann Clin Microbiol Antimicrob. 2013;12(1):11. https://doi.org/10.1186/14760711-12-11.

18. Davies J, Davies D. Resistance origins and evolution of antibiotic. Microbiology and molecular biology reviews. Microbiol Mol Biol Rev. 2010; 74(3):417-33. https://doi.org/10.1128/MMBR.00016-10.

19. Hersh AL, Chambers HF, Maselli JH, Gonzales R. National trends in ambulatory visits and antibiotic prescribing for skin and soft-tissue infections. Arch Intern Med. 2008;168(14):1585-91. https://doi.org/10.1001/a rchinte.168.14.1585.

20. Murawala S, Vegad M, Patel F, Shah P, Patel V. A study on prevalence and antimicrobial resistance pattern of community acquired gram negative uropathogens at tertiary care teaching hospital, Ahmedabad. Int J Res Med. 2016;5(2):150-5

21. Perera $\mathrm{V}$, Brahmanayake BSAJP, Basnayake $\mathrm{P}$, et al. A retrospective study of methicillin-resistant Staphylococcus aureus (MRSA) infections in a private hospital in Sri Lanka. Bull Sri Lanka College Microbiol. 2015;13(1):22.

22. Jayatilleke K, Bandara P. Antibiotic sensitivity pattern of Staphylococcus aureus in a tertiary care hospital of Sri Lanka. Sri Lankan J Infect Dis. 2012;2(2).

23. Edslev SM, Westh H, Andersen PS, Skov R, Kobayashi N, Bartels MD, et al. Identification of a PVL-negative SCCmec-IVa sublineage of the methicillinresistant Staphylococcus aureus CC80 lineage: understanding the clonal origin of CA-MRSA. Clin Microbiol Infect. 2018;24(3):273-8. https://doi.org/1 0.1016/j.cmi.2017.06.022.

24. Chirindze LM, Zimba TF, Sekyere JO, Govinden U, Chenia HY, Sundsfjord A, et al. Faecal colonization of E. coli and Klebsiella spp. producing extendedspectrum beta-lactamases and plasmid-mediated AmpC in Mozambican university students. BMC Infect Dis. 2018;18(1):1-8.

25. Stoesser N, Xayaheuang S, Vongsouvath M, Phommasone K, Elliott I, del Ojo EC, et al. Colonization with Enterobacteriaceae producing ESBLs in children 
attending pre-school childcare facilities in the Lao People's Democratic Republic. J Antimicrob Chemother. 2015;70(6):1893-7. https://doi.org/10.1 093/jac/dkv021.

26. Nanayakkara D, Liyanapathirana V, Kandauda C, Gihan C, Ekanayake A, Adasooriya D. Maternal vaginal colonization with selected potential pathogens of neonatal sepsis in the era of antimicrobial resistance, a single center experience from Sri Lanka. BMC Infect Dis. 2018;18(1):351. https://doi. org/10.1186/s12879-018-3262-y.

27. Gysin DV, et al. Session : P023 Reducing MDR Gram-negatives - myths and facts Category: 8d, Nosocomial infection surveillance \& epidemiology Extended-spectrum beta-lactamase producing Enterobacteriaceae among healthy pregnant women in Switzerland : preliminary results of an ongoing cross-sectional study Hospital Basel. Proceedings of the ECCMID sessions, Viena, vol. 5; 2017. p. 2-3.

28. Laupland KB, Church DL, Vidakovich J, Mucenski M, Pitout JD. Communityonset extended-spectrum $\beta$-lactamase (ESBL) producing Escherichia coli: importance of international travel. J Infect. 2008:57(6):441-8. https://doi. org/10.1016/j.jinf.2008.09.034.

29. Lübbert C, Straube L, Stein C, Makarewicz O, Schubert S, Mössner J, et al. Colonization with extended-spectrum beta-lactamase-producing and carbapenemase-producing Enterobacteriaceae in international travelers returning to Germany. Int J Med Microbiol. 2015;305(1):148-56. https://doi. org/10.1016/j.jmm.2014.12.001.

30. Kumudunie WG, Wijesooriya LI, Namalie KD, Sunil-Chandra NP, Wijayasinghe YS. Epidemiology of multidrug-resistant Enterobacteriaceae in Sri Lanka: first evidence of blaKPC harboring Klebsiella pneumoniae. J Infect Public Health. 2020;13(9):1330-5. https://doi.org/10.1016/j.jiph.2020.04.010

31. Tissera K, Liyanapathirana V, Dissanayake N, Pinto V, Ekanayake A, Tennakoon M, et al. Spread of resistant gram negatives in a Sri Lankan intensive care unit. BMC Infect Dis. 2017;17(1):490. https://doi.org/10.1186/ s12879-017-2590-7.

32. Gamblin J, Jefferies JM, Harris S, Ahmad N, Marsh P, Faust SN, et al. Nasal self-swabbing for estimating the prevalence of Staphylococcus aureus in the community. J Med Microbiol. 2013;62(Pt 3):437-40. https://doi.org/10.1 099/jmm.0.051854-0 Epub 2012 Dec 6. PMID: 23222858.

33. Hogan B, Rakotozandrindrainy R, Al-Emran H, Dekker D, Hahn A, Jaeger A, et al. Prevalence of nasal colonisation by methicillin-sensitive and methicillin-resistant Staphylococcus aureus among healthcare workers and students in Madagascar. BMC Infect Dis. 2016;16(1):420. https://doi.org/10.11 86/s12879-016-1733-6 PMID: 27526771; PMCID: PMC4986198.

34. Sun J, Yang M, Sreevatsan S, Bender JB, Singer RS, Knutson TP, et al. Longitudinal study of Staphylococcus aureus colonization and infection in a cohort of swine veterinarians in the United States. BMC Infect Dis. 2017; 17(1):690. https://doi.org/10.1186/s12879-017-2802-1 PMID: 29052523; PMCI D: PMC5649086.

35. Lautenbach E, Harris AD, Perencevich EN, Nachamkin I, Tolomeo P, Metlay JP. Test characteristics of perirectal and rectal swab compared to stool sample for detection of fluoroquinolone-resistant Escherichia coli in the gastrointestinal tract. Antimicrob Agents Chemother. 2005;49(2):798-800. https://doi.org/10.1128/AAC.49.2.798-800.2005 PMID: 15673772; PMCID: PMC547369.

36. Blyth DM, Mende K, Maranich AM, Beckius ML, Harnisch KA, Rosemann CA et al. Antimicrobial resistance acquisition after international travel in U.S. travelers. Trop Dis Travel Med Vaccines. 2016;2:4. https://doi.org/10.1186/s4 0794-016-0020-2 PMID: 28883948; PMCID: PMC5531010.

\section{Publisher's Note}

Springer Nature remains neutral with regard to jurisdictional claims in published maps and institutional affiliations.

Ready to submit your research? Choose BMC and benefit from:

- fast, convenient online submission

- thorough peer review by experienced researchers in your field

- rapid publication on acceptance

- support for research data, including large and complex data types

- gold Open Access which fosters wider collaboration and increased citations

- maximum visibility for your research: over $100 \mathrm{M}$ website views per year

At BMC, research is always in progress.

Learn more biomedcentral.com/submissions 